Supporting Information

\title{
Adaptable reversibly interlocked networks from immiscible polymers enhanced by hierarchy induced multilevel energy consumption mechanisms
}

Yang You', Min Zhi Rong ${ }^{a,}$, and Ming Qiu Zhang, *

a Materials Science Institute, Key Laboratory for Polymeric Composite and Functional Materials of Ministry of Education, GD HPPC Lab, School of Chemistry, Sun Yat-Sen University, Guangzhou, 510275, P. R. China

*Email: cesrmz@mail.sysu.edu.cn (Min Zhi Rong)

*Email: ceszmq@mail.sysu.edu.cn (Ming Qiu Zhang)

Contents of the Supporting Information

Number of pages of SI: 33

Number of Figures in SI: 15 
Number of Tables in SI: 6

Miscibility of the parent polymers

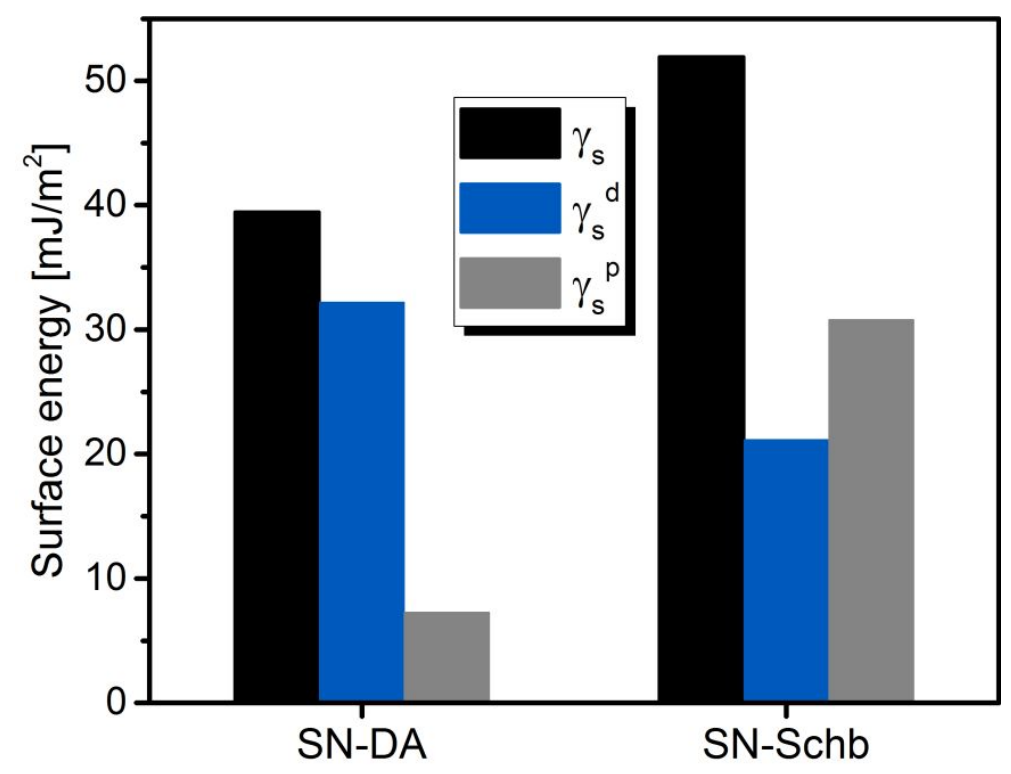

Figure S1 Surface energies of the two single networks.

Table S1 Solvent uptake, $U$, and gel content, $G$, of the two single networks

\begin{tabular}{|c|c|c|c|c|}
\hline \multirow{2}{*}{ Single } & \multicolumn{2}{|c|}{ THF } & \multicolumn{2}{c|}{ Water } \\
\cline { 2 - 5 } & $U(\mathrm{wt} \%)$ & $G(\mathrm{wt} \%)$ & $U(\mathrm{wt} \%)$ & $G(\mathrm{wt} \%)$ \\
\hline SN-DA & 359.48 & 98.41 & 1.55 & 100.00 \\
\hline SN-Schb & 6.63 & 99.36 & \multicolumn{2}{c|}{ Soluble } \\
\hline
\end{tabular}


To investigate miscibility of the modified polymers, surface energies of the two single networks are tested by contact angle measurements. As shown in Figure S1, surface energy of SN-DA $\left(34.51 \mathrm{~mJ} / \mathrm{m}^{3}\right)$ is much lower than that of SN-Schb $(51.97$ $\mathrm{mJ} / \mathrm{m}^{2}$ ), probably because the abundant polar groups of PEI have endowed SN-Schb with higher $\gamma_{S}^{p}\left(30.81 \mathrm{~mJ} / \mathrm{m}^{2}\right)$. The difference of the two components in surface energy can also be revealed by the swelling experiment (Table S1): SN-DA is excessively swollen in THF, while SN-Schb is nearly not swollen in the same solvent. When water is used instead, SN-DA is not swollen and SN-Schb completely dissolves because of the exchange reaction between Schiff base and the excess primary amine/other Schiff base. The above results confirm the immiscibility of two single networks. 


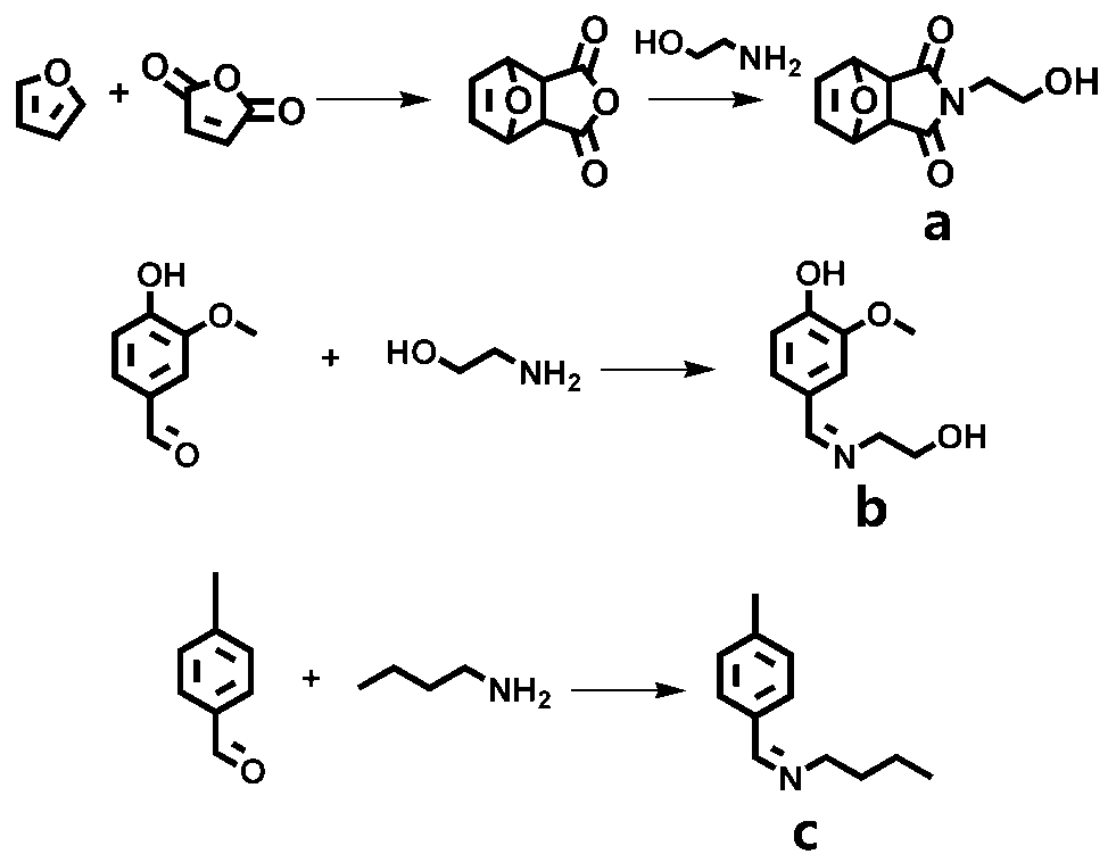

Figure S2 Synthesis of the model compounds

DA adduct a was synthesized according to our previous report. ${ }^{\mathrm{S} 1}$ Maleic anhydride (20 g, $0.204 \mathrm{~mol}$ ) was dissolved in $50 \mathrm{~mL}$ anhydrous dioxane and charged to a flame dried $100 \mathrm{~mL}$ round-bottom flask with a magnetic stir bar. $15 \mathrm{~mL}$ furan was added using syringe and the solution was stirred at room temperature for $30 \mathrm{~min}$. The flask was sealed and kept at room temperature overnight. The precipitate was collected via vacuum filtration and washed with diethyl ether. The colorless crystal (5 g, 0.030 mol) was suspended in $7 \mathrm{~mL} \mathrm{MeOH}$ in a flame dried $50 \mathrm{~mL}$ three-neck round-bottom flask with a magnetic stir bar and reflux condenser. The solution was purged with nitrogen for $10 \mathrm{~min}$ in an ice bath, after which ethanolamine $(1.84 \mathrm{~g}, 0.030 \mathrm{~mol})$ in 3 
$\mathrm{mL} \mathrm{MeOH}$ was added dropwise via a dropping funnel. The resultant solution was stirred for $5 \mathrm{~min}$ at $0{ }^{\circ} \mathrm{C}$, and then refluxed for $24 \mathrm{~h}$. The flask was cooled to room temperature, and stored in a freezer overnight. The precipitate was collected by vacuum filtration. The produced white crystals were washed with 2-propanol and used without further purification. ${ }^{1} \mathrm{H}-\mathrm{NMR}$ of DA adduct a (400 MHz, DMSO-d $\left.{ }_{6}\right)(\mathrm{ppm})$ : $6.55(\mathrm{~s}, 2 \mathrm{H}), 5.13(\mathrm{~s}, 2 \mathrm{H}), 4.78(\mathrm{~s}, 1 \mathrm{H}), 3.42(\mathrm{~s}, 4 \mathrm{H})$, and $2.93(\mathrm{~s}, 2 \mathrm{H})$.

To synthesis Schiff base b, vanillin (1.52 g, $0.010 \mathrm{~mol})$ and ethanolamine (0.61 g, $0.010 \mathrm{~mol}$ ) were dissolved in $20 \mathrm{~mL} \mathrm{MeOH}$, and the mixture was stirred at room temperature for $24 \mathrm{~h}$. Afterwards, orange product was obtained after rotary evaporation. ${ }^{1} \mathrm{H}-\mathrm{NMR}$ of Schiff base $\mathbf{b}\left(400 \mathrm{MHz}, \mathrm{DMSO}_{6}\right)(\mathrm{ppm}): 8.15(\mathrm{~s}, 1 \mathrm{H})$, $7.33(\mathrm{~d}, 1 \mathrm{H}), 7.09(\mathrm{~d}, 1 \mathrm{H}), 6.82(\mathrm{~d}, 1 \mathrm{H}), 3.79(\mathrm{~s}, 3 \mathrm{H}), 3.62(\mathrm{~m}, 2 \mathrm{H})$, and $3.58(\mathrm{~m}, 2 \mathrm{H})$.

Similarly, Schiff base c was synthesized using p-methyl benzaldehyde and nbutylamine as reagents. ${ }^{1} \mathrm{H}-\mathrm{NMR}$ of Schiff base c (400 MHz, DMSO-d $\left.{ }_{6}\right)(\mathrm{ppm}): 8.28$ $(\mathrm{s}, 1 \mathrm{H}), 7.63(\mathrm{~d}, 2 \mathrm{H}), 7.25(\mathrm{~d}, 2 \mathrm{H}), 3.53(\mathrm{t}, 2 \mathrm{H}), 2.34(\mathrm{~s}, 3 \mathrm{H}), 1.58(\mathrm{~m}, 2 \mathrm{H}), 1.34(\mathrm{~m}$, $2 \mathrm{H})$, and $0.91(\mathrm{t}, 3 \mathrm{H})$. 


\section{Chemical structures of the single networks}

(a)

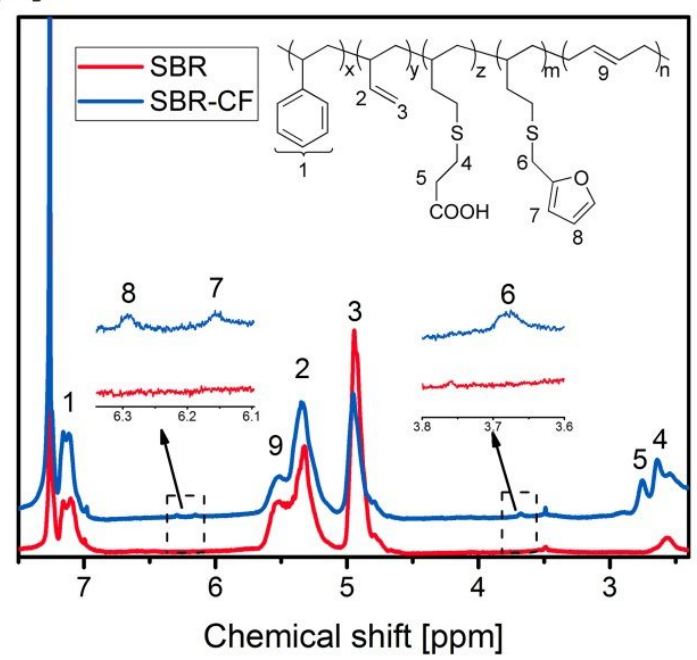

(b)

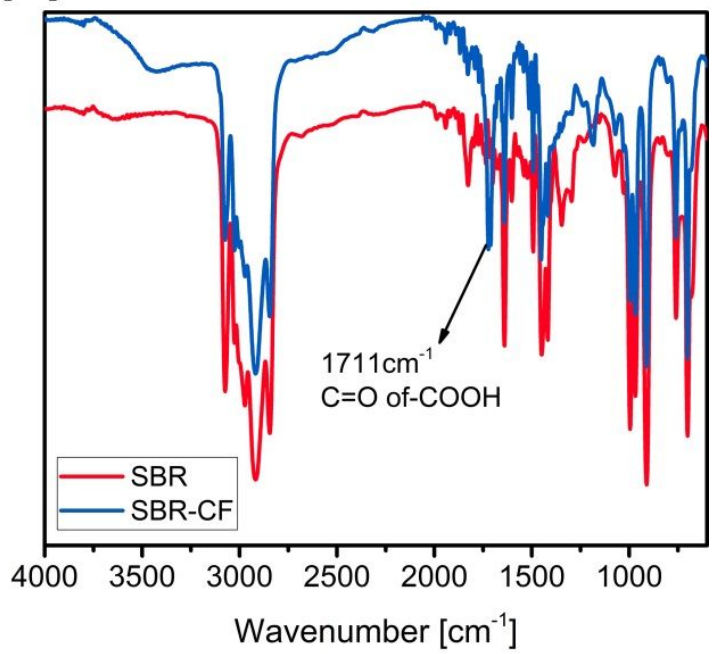

Figure S3 (a) ${ }^{1} \mathrm{H}-\mathrm{NMR}$ spectra and (b) FTIR spectra of the raw SBR and modified SBR.

Thiol-ene click reaction is a frequently-used method to modify polymers with alkenes. In the present work, the solution-polymerized SBR was grafted with carboxyl groups and furan rings using 1907 initiator. Figure S3a shows the ${ }^{1} \mathrm{H}-\mathrm{NMR}$ spectra of SBR and grafted SBR-CF. The appearance of the new peaks at 6.293, 6.157, 3.675, 2.754 and $2.641 \mathrm{ppm}$, accompanied with the weakening of the peak at $4.952 \mathrm{ppm}$, indicates that carboxyl groups and furan rings have been successfully grafted onto the pendent vinyl groups of the SBR chains. The grafting ratios of furan ring $\left(R g_{F u}\right)$ and carboxyl group $\left(\mathrm{Rg}_{\mathrm{COOH}}\right)$ were calculated from the ${ }^{1} \mathrm{H}-\mathrm{NMR}$ spectra according to the following equations: ${ }^{\mathrm{S} 2}$ 


$$
\begin{gathered}
R g_{F u}=\frac{A_{3.675}}{A_{3.675}+A_{2.754}+A_{4.952}} \times 56.6 \% \\
R g_{\text {COOH }}=\frac{A_{2.754}}{A_{3.675}+A_{2.754}+A_{4.952}} \times 56.6 \%
\end{gathered}
$$

where $A_{x}$ represents the integral area of the proton peak at $\delta=\mathrm{x}$. The values of $\operatorname{Rg}_{\mathrm{COOH}}$ and $R g_{F u}$ were estimated to be $10.69 \%$ and $1.24 \%$ respectively, close to the theoretical values $(11.16 \%$ and $1.31 \%)$.

As for the FTIR spectra of SBR and SBR-CF (Figure S3b), an absorption appears at $1711 \mathrm{~cm}^{-1}$ after the modification, which is attributed to the stretching vibration of $\mathrm{C}=\mathrm{O}$ and proves the successful modification of SBR chains as planned. 
(a)

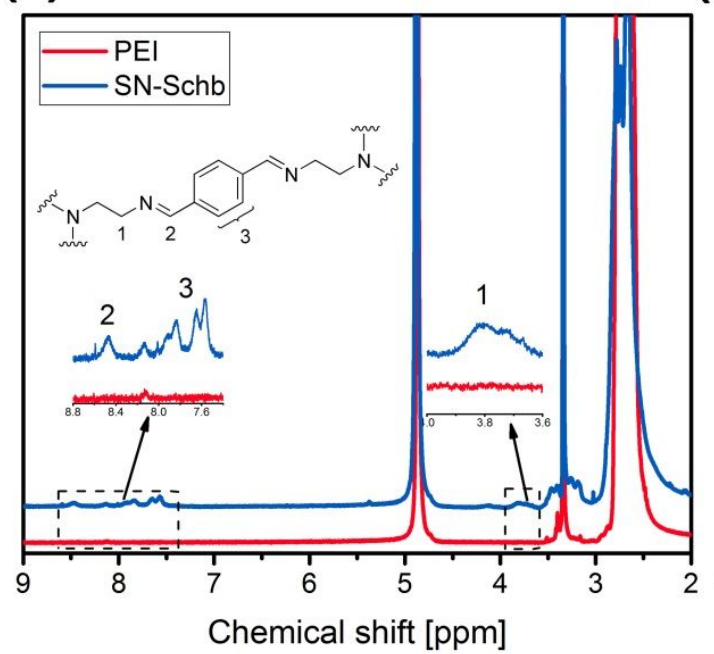

(c)

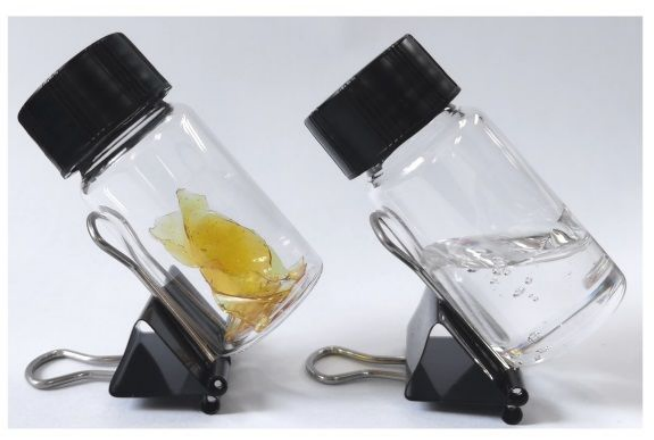

(b)

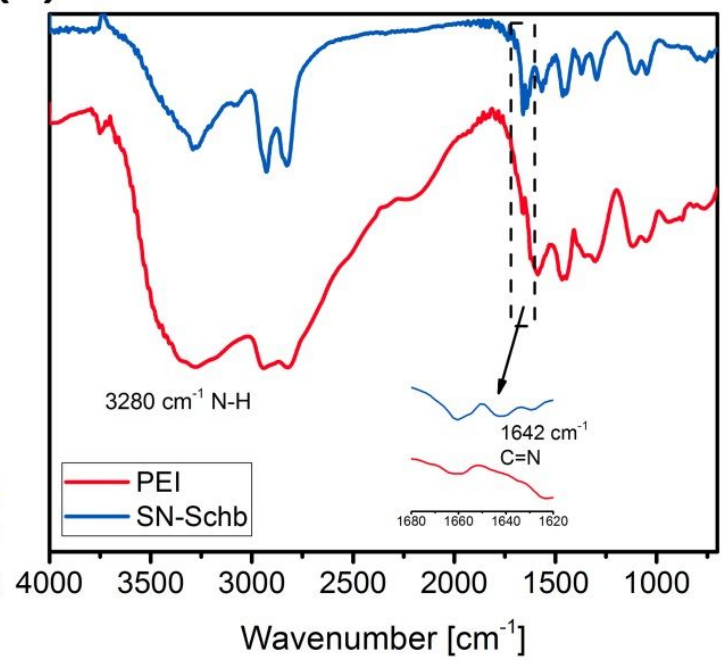

(d)

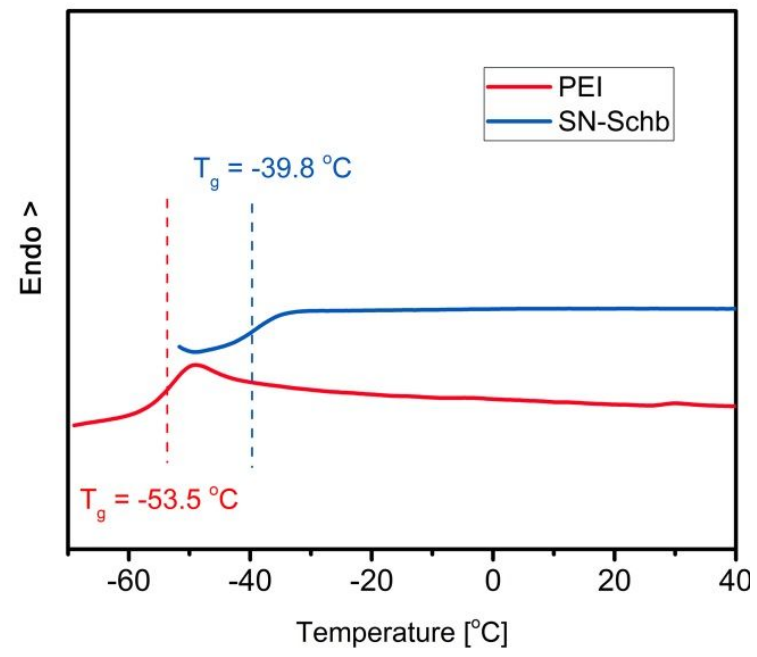

Figure S4 (a) ${ }^{1} \mathrm{H}-\mathrm{NMR}$ spectra, (b) FTIR spectra, (c) optical images, and (d) DSC heating traces (heating rate: $10^{\circ} \mathrm{C} / \mathrm{min}$ ) of PEI and SN-Schb.

PEI (average number of amino groups per molecule is about 233, including 35 mol\% primary amine, $35 \mathrm{~mol} \%$ secondary amine, and $30 \mathrm{~mol} \%$ tertiary amine) was crosslinked with 1,4-phthalaldehyde. Only $\sim 9 \mathrm{~mol} \%$ primary amine was reacted to build a loosely crosslinked network, and a large amount of amino groups were 
reserved for the subsequent interaction with carboxyl groups of SBR chains. The ${ }^{1} \mathrm{H}-$ NMR spectra (Figure S4a) indicate the new resonances at $8.465 \mathrm{ppm}(-\mathrm{CH}=\mathrm{N}-)$ and 3.807 ppm $\left(-\mathrm{CH}_{2}-\mathrm{CH}=\mathrm{N}-\right)$ arise, which confirms that aldehyde has reacted with primary amine to give Schiff base. On the FTIR spectra of PEI and SN-Schb (Figure S4b), both the reduction of the peak at $3280 \mathrm{~cm}^{-1}$ and the arise of the absorption peak at $1642 \mathrm{~cm}^{-1}$ are observed, as the amine-aldehyde reaction happens. After the crosslinking, the colorless fluid-state PEI turns to be yellow solid-state SN-Schb (Figure S4c) and the glass transition temperature detected by DSC increases from $53.5^{\circ} \mathrm{C}$ to $-39.8^{\circ} \mathrm{C}$ (Figure $\left.\mathbf{S 4 d}\right)$. 
Formation of the ionic interactions

Table S2 Swelling properties of the interlocked networks and controls.

\begin{tabular}{|c|c|c|c|c|}
\hline \multirow{2}{*}{ Samples } & \multicolumn{2}{|c|}{ THF } & \multicolumn{2}{c|}{ Water } \\
\cline { 2 - 5 } & $U(\mathrm{wt} \%)$ & $G(\mathrm{wt} \%)$ & $U(\mathrm{wt} \%)$ & 99.69 \\
\hline ILN-201 & 334.84 & 98.42 & 2.15 & 99.68 \\
\hline ILN-202 & 341.51 & 98.54 & 1.57 & 96.00 \\
\hline ILN-203 & 301.91 & 97.38 & 9.72 & 93.85 \\
\hline ILN-204 & 311.97 & 95.43 & 15.3 & 92.31 \\
\hline Control-202 & 294.15 & 97.60 & 12.22 & 97.16 \\
\hline Control-IPN & 311.67 & 95.91 & 14.80 & 95 \\
\hline Control-COOH free & 512.08 & 94.25 & 10.96 & \\
\hline & & & & \\
\hline
\end{tabular}

As shown in Table S2, the solvent uptakes and gel contents of ILN-201 and ILN202 in the two solvents are similar and close to those of SN-DA, since the hydrophilic amino groups are fully bonded with carboxyl groups and surrounded by the hydrophobic rubber. With respect to ILN-203 and ILN-204, the uptake of water increases and that of THF decreases. Meanwhile, gel contents in both the two solvents decrease. The reason might be the excess SN-Schb is not fully bonded. They tend to contact with the solvent molecules or exchange with neighboring Schiff base. 
Similarly, as proved by the FTIR spectra in Figure 4a, the same situation occurs in the controls. Control-202 lacks the interlocked structure, and the PEI chains have collapsed to form PEI-rich domains. In the case of Control-IPN, excess SN-Schb is absorbed by the ionic interactions. With respect to Control-COOH free, carboxyl groups are absent. Therefore, all the three controls possess lower gel contents.

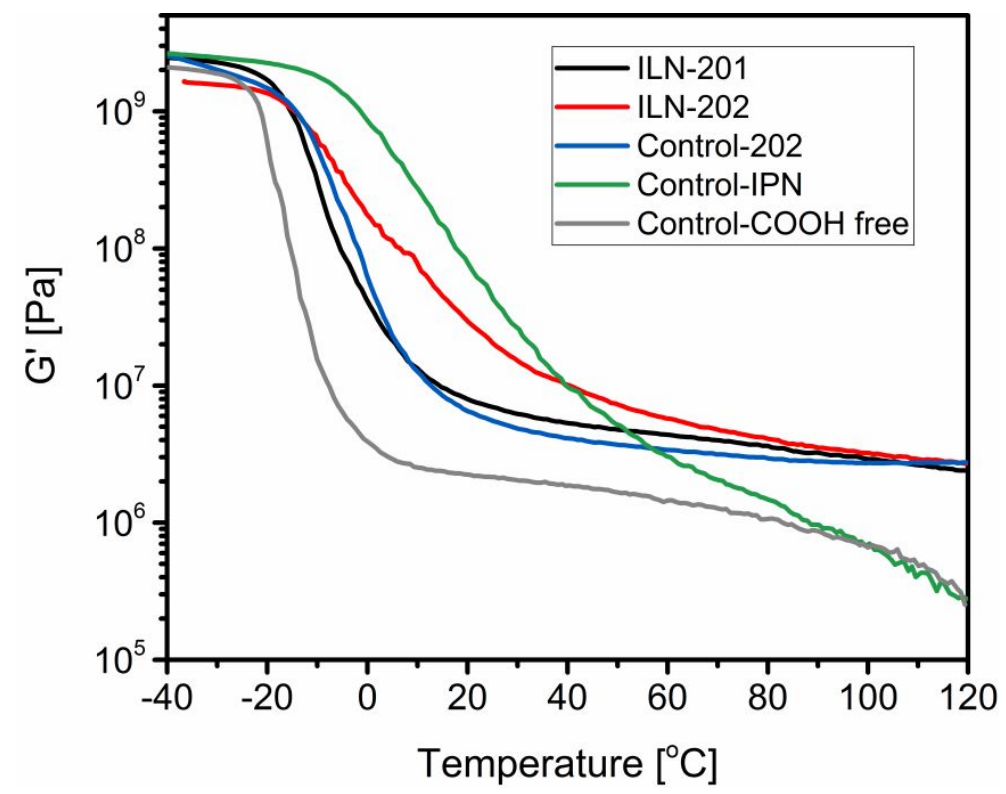

Figure S5 Temperature dependences of $G^{\prime}$ of ILN-201, ILN-202 and the controls. 
Reversibility of the ionic interactions

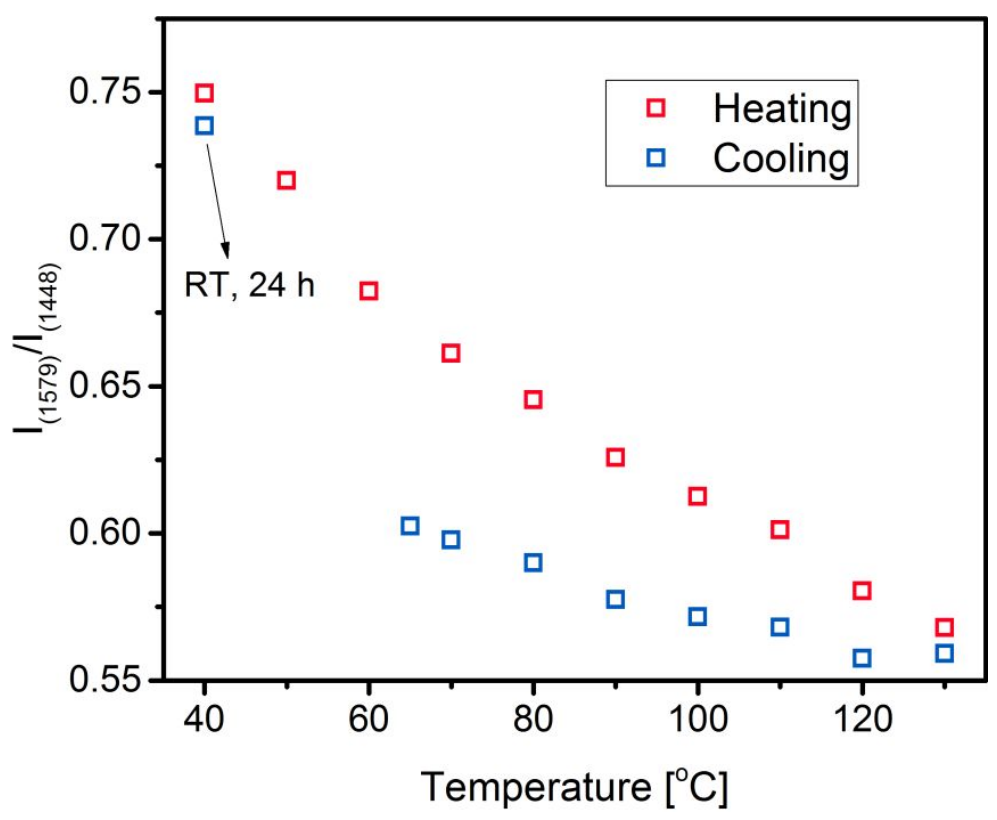

Figure S6 FTIR intensity ratio of the absorption at $1579 \mathrm{~cm}^{-1}$ to that at $1448 \mathrm{~cm}^{-1}$ as a function of temperature.

As shown in Figure S6, the intensity recovery rate during cooling is slower than the fading rate during heating, which is understandable because re-bonding of the inter-macromolecular ionic interactions requires the time consuming chain rearrangement. 
Table S3 Energy dissipation and residual strain determined during cyclic tensile tests

\begin{tabular}{|c|c|c|c|c|c|}
\hline \multirow{2}{*}{ Samples } & \multicolumn{3}{|c|}{ Energy dissipation, $W\left(\mathrm{MJ} / \mathrm{m}^{3}\right)$} & \multicolumn{2}{c|}{ Residual strain (\%) } \\
\cline { 2 - 6 } & $1^{\text {st }}$ cycle & $2^{\text {nd }}$ cycle & $3^{\text {rd }}$ cycle & $2^{\text {nd }}$ cycle & $3^{\text {rd }}$ cycle \\
\hline SN-DA & 0.41 & 0.15 & 0.14 & 19.3 & 21.7 \\
\hline ILN-202 & 2.58 & 1.30 & 1.15 & 17.63 & 20.2 \\
\hline Control-202 & 1.25 & 0.68 & 0.62 & 25.5 & 28.5 \\
\hline Control-IPN & 2.52 & 1.27 & 1.14 & 23.3 & 28.6 \\
& & & & & \\
\hline
\end{tabular}

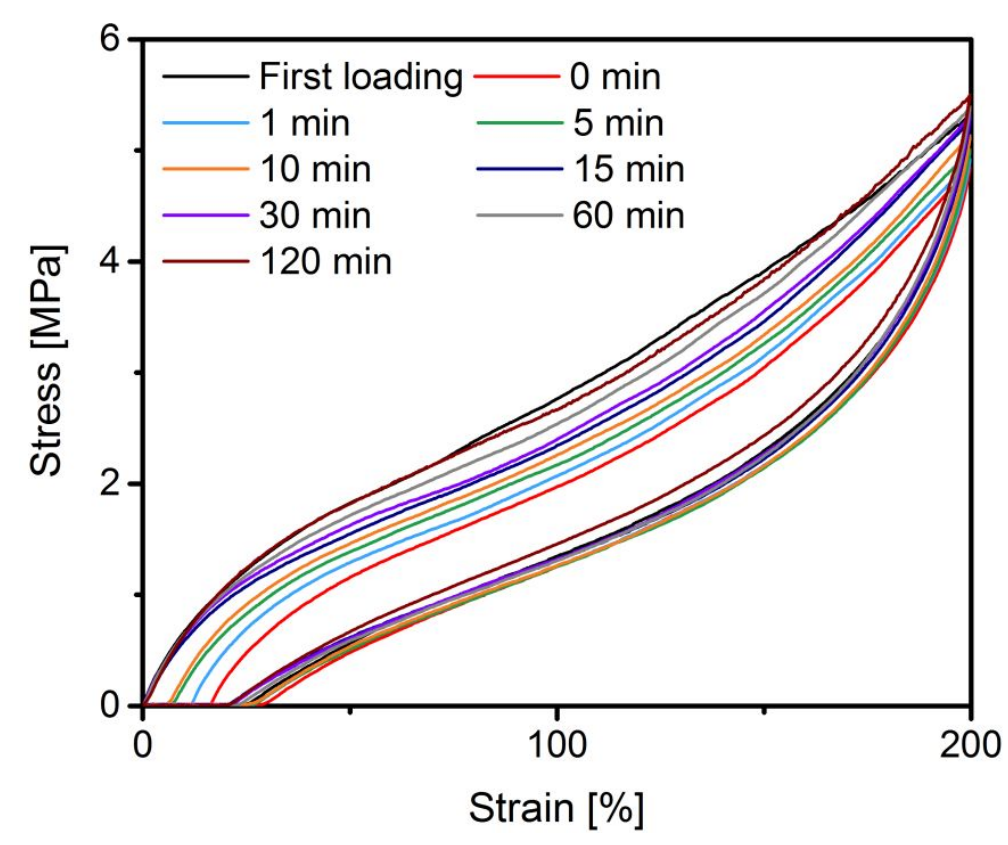

Figure S7 Cyclic tensile curves of ILN-202 with different resting times. Note: the maximum strain $=200 \%$; crosshead speed $=20 \mathrm{~mm} / \mathrm{min}$. 
(a)

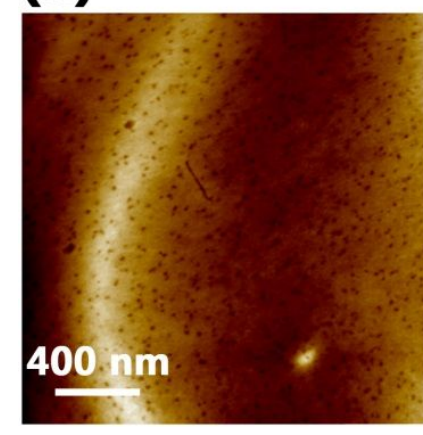

(b)

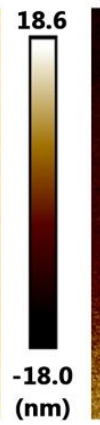

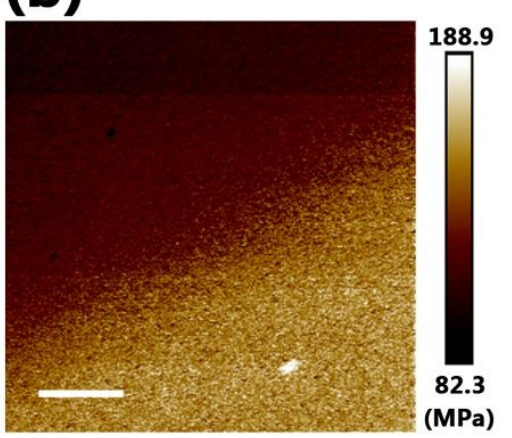

(c)

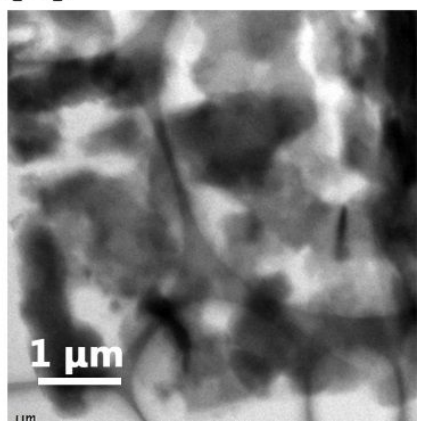

Figure S8 (a) AFM height profile of Control-202. (b) Nano-modulus mapping of Control-202. (c) TEM image of Control-202.

(a)

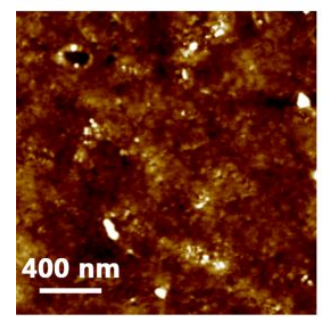

(e)

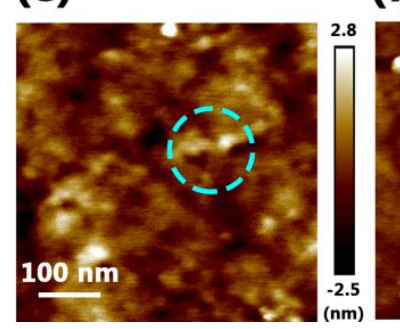

(b)

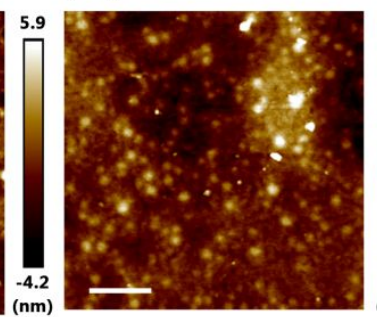

(f)

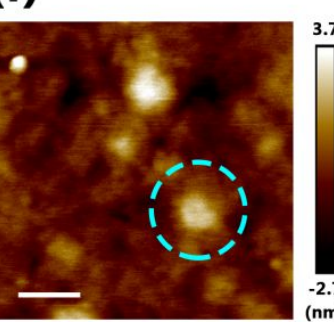

(c)

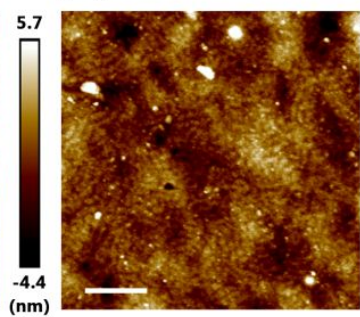

(g)

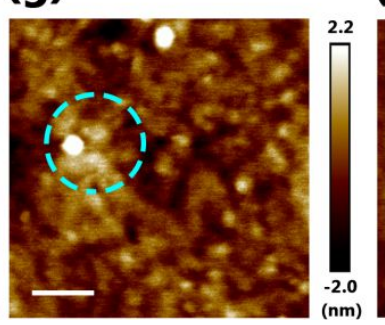

(d)

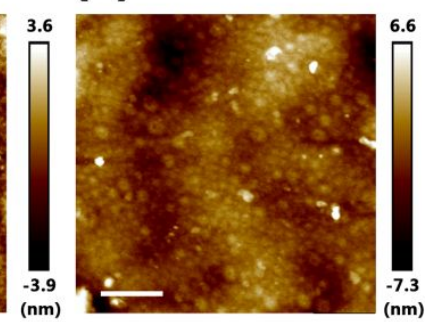

(h)

Figure S9 AFM height profiles of (a, e) ILN-201, (b, f) ILN-202, (c, g) ILN-203, and (d, h) ILN-204. The circled regions highlight the aggregated ionic complexes. 
Figure S9 shows the surface morphologies of different ILNs. For ILN-201, the aggregates are sparse, because only half of -COOH are ionized. While for ILN-203 and ILN-204, the amounts of the aggregates increase and the alignments become closer, since more primary amine are ionized.

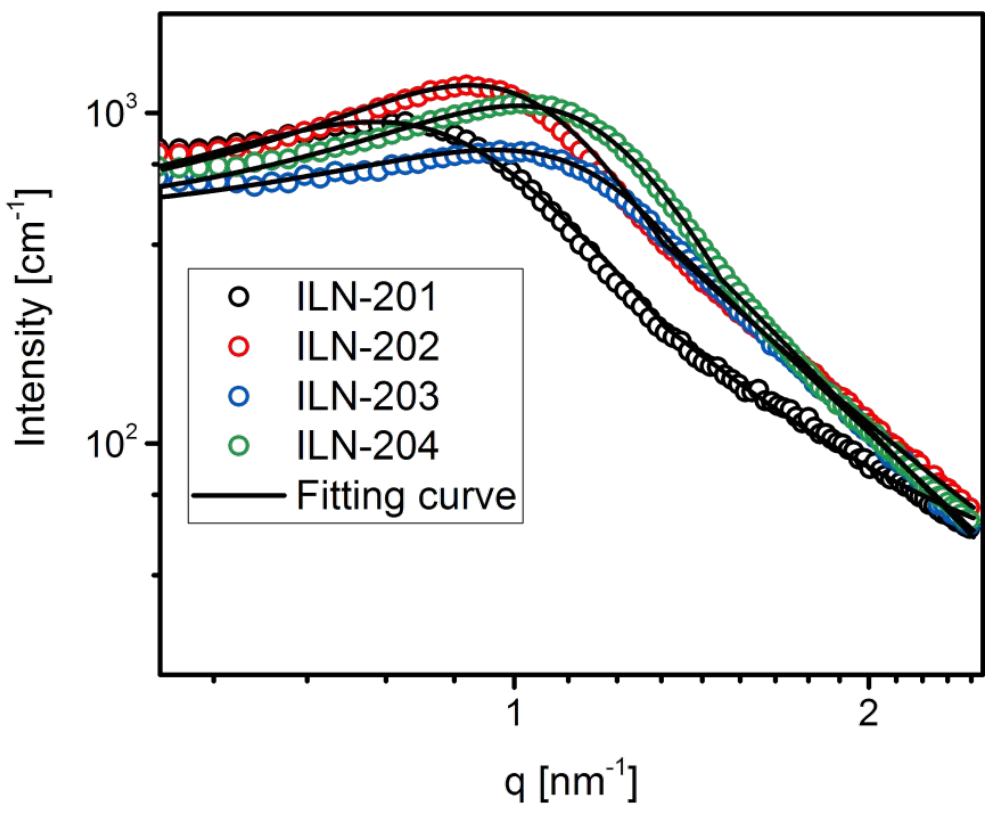

Figure S10 Fitting of SAXS profiles of the interlocked networks

The experimental scattering patterns $\left(0.5-1.5 \mathrm{~nm}^{-1}\right)$ are fitted using Yarusso-Copper model $^{\mathrm{S} 3}$ (Figure S10). In this model, the ionic clusters are assumed to be a spherical particle composed of an ionic core with a radius of $R_{l}$ and a shell with a thickness of $R_{C A}-R_{l}$. The scattering intensity is presented as: 


$$
\begin{gathered}
I(q)=K \frac{V_{1}^{2}}{V_{P}} \phi\left(q R_{1}\right)^{2} \frac{1}{1+\left(\frac{8 V_{C A}}{V_{P}}\right) \phi\left(2 q R_{C A}\right)} \\
V_{C A}=\frac{4}{3} \pi R_{C A}{ }^{3} \\
V_{1}=\frac{4}{3} \pi R_{1}{ }^{3} \\
\phi(x)=3 \frac{\sin x-x \cos x}{x^{3}}
\end{gathered}
$$

where $K$ is the adjustable parameter for scattering intensity and $V_{P}$ is the average volume occupied by one particle, which is also assumed to be a sphere with a radius of $r$. Thus, the average distance between two neighboring ionic cores, $d_{P}$, can be defined as $2 r-2 R_{1}$.

Table S4 Structural parameters of the interlocked networks obtained from SAXS characterization

\begin{tabular}{|c|c|c|c|c|}
\hline ILNs & $R_{1}(\mathrm{~nm})$ & $R_{C A},(\mathrm{~nm})$ & $d_{P},(\mathrm{~nm})$ & $V_{P}\left(\mathrm{~nm}^{3}\right)$ \\
\hline ILN-201 & 2.04 & 3.29 & 5.99 & 534.87 \\
\hline ILN-202 & 2.00 & 2.78 & 3.47 & 218.99 \\
\hline ILN-203 & 1.90 & 2.39 & 3.38 & 193.29 \\
\hline ILN-304 & 1.87 & 2.46 & 3.04 & 162.68 \\
\hline
\end{tabular}


As exhibited in Table S4, $V_{P}$ decreases from $534.87 \mathrm{~nm}^{3}$ to $218.99 \mathrm{~nm}^{3}$ as the mass ratio of SN-Schb increases from 1:20 to 2:20. It means that more ionic clusters have been generated in ILN-202 as a result of ionization of -COOH. With increasing the mass ratio of SN-Schb, $V_{P}$ further decreases because more and more primary amine on the chain ends is ionized, and the ionized groups are more likely to aggregate due to the smaller steric hindrance. ${ }^{\mathrm{S}}$ Besides, the particles size slightly decreases with a rise in the mass ratio of SN-Schb. This is understandable as the Schiff base bond is less stable than DA bond, and the PEI chains are much shorter than SBR chains, leading to less chain entanglement between the ionic cores and the matrix.

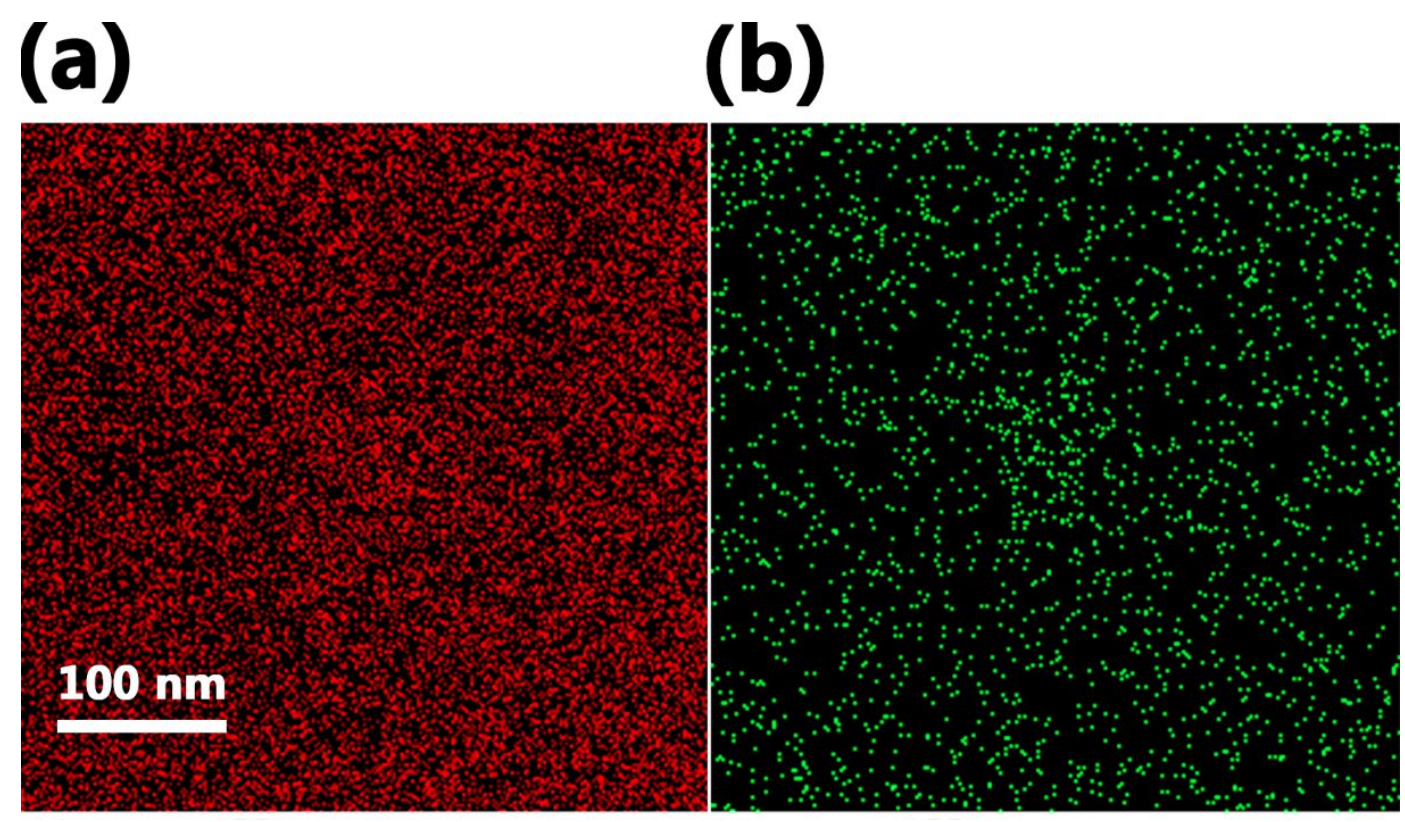

Figure S11 Distribution of (a) carbon and (b) nitrogen in ILN-202 tested by TEMEDS. 


\section{(a)}

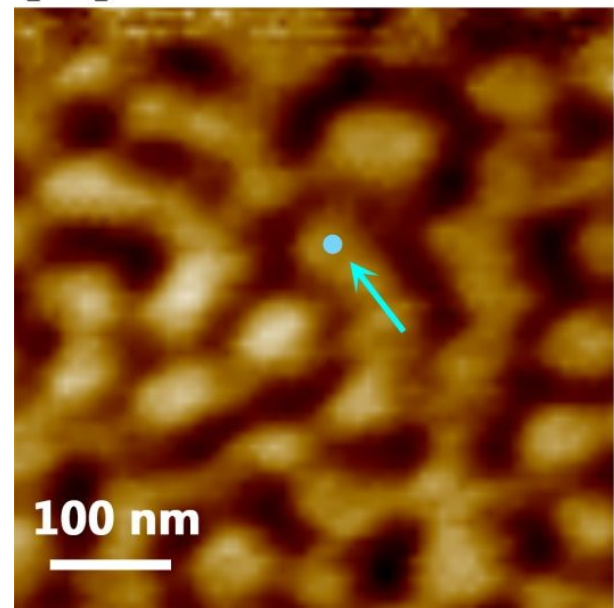

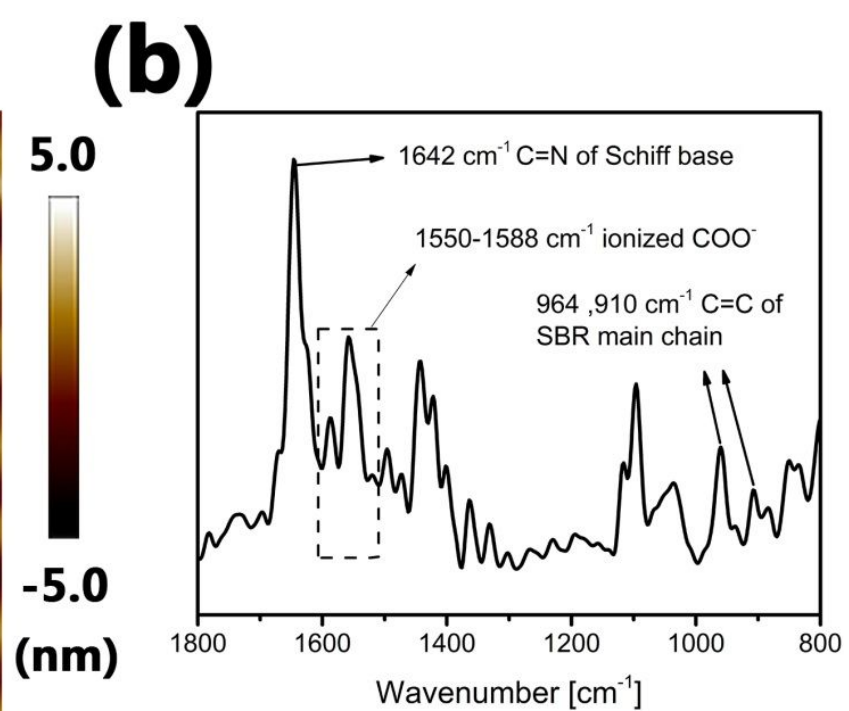

Figure S12 Nano-IR results of ILN-204. (a) Height image and (b) IR spectrum collected from the sky-blue region near the center of (a). 


\section{Mechanical properties}

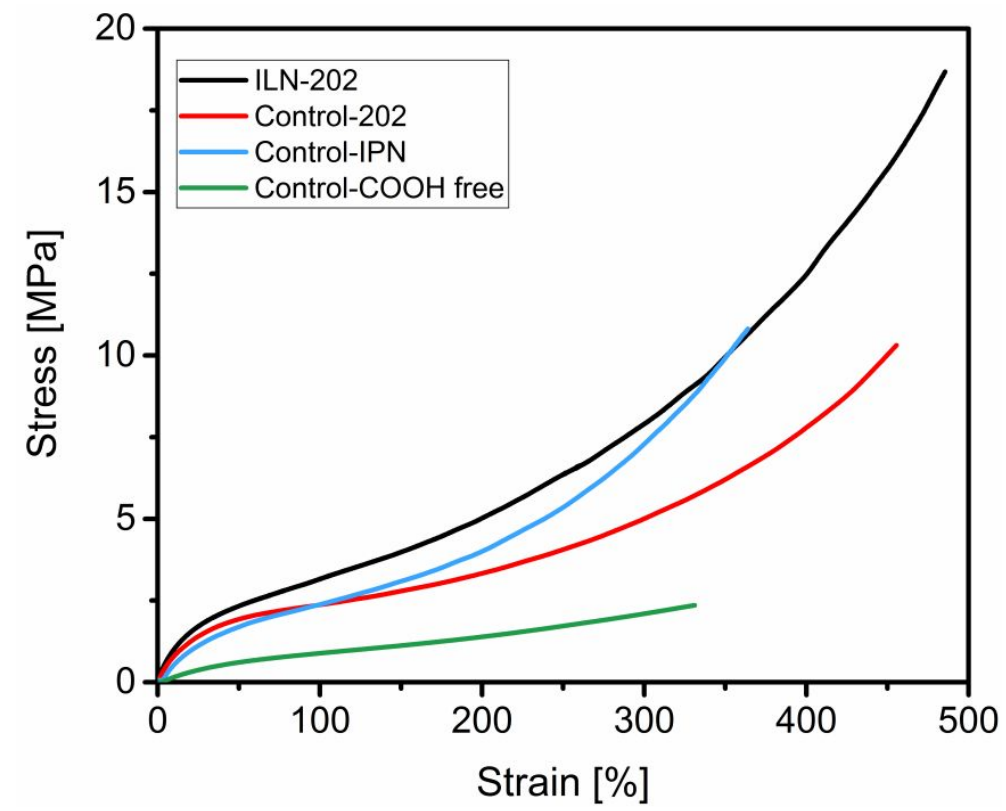

Figure S13 Typical tensile stress-strain curves of ILN-202 and the controls.

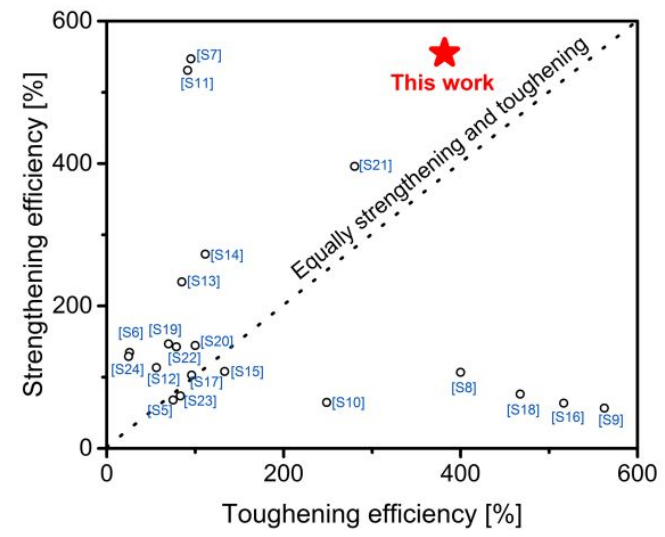

[S5] PS/SCA-Zn

[S6] PU/Surlyn 8150/lignin

[S7] XNBR/PMMA

[S8] PVDF/MMA-BA-IL

[S9] PLA/i-BIIR

[S10] PLA/EMAA-Zn

[S11] XNBR/m-EPDM/ZnO

[S12] Zn-NMR/XNBR

[S13] Zn-mEPDM/PEA

[S14] PP/Zn-SEPDM
[S15] ABS/Na-SSAN

[S16] K-HXSBR/PE

[S17] PP/Zn-s-SBR

[S18] Novatein/Surlyn 9320

[S19] PBI/SPEEK

[S20] Chitosan/PAA

[S21] bPEI/PAA/PEO

[S22] Zn-PEA/ENR

[S23] Zn-PEMA/EVOH

[S24] PBI/FAA3i

Figure S14 Comparison of tensile properties of ILN-202 and those of a few multicomponent polymer systems with ionic interactions. ${ }^{55-S 24}$ The strengthening efficiency is defined as the ratio of tensile strength of ILNs or polymer blends to that of the parent single networks or component polymers, while the toughening efficiency 
is estimated from the ratio of failure strain/fracture toughness/impact strength of ILNs or polymer blends to that of the parent single networks or component polymers. Note: For ILNs, the mechanical properties of SN-DA are used as the reference data to calculate the strengthening and toughening efficiencies. This is because SN-Schb is very weak. If its mechanical properties are used for the calculation, the strengthening and toughening efficiencies would be extremely high.

Table S5 Mechanical properties of elastomers based on hybrid networks*

\begin{tabular}{|c|c|c|c|c|c|}
\hline Elastomers & $\begin{array}{l}\text { Crosslinking } \\
\text { bonds }\end{array}$ & $\begin{array}{l}\text { Miscibility and } \\
\text { homogeneity }\end{array}$ & $\begin{array}{l}\text { Tensile } \\
\text { strength } \\
(\mathrm{MPa})\end{array}$ & $\begin{array}{c}\text { Failure } \\
\text { strain } \\
(\%)\end{array}$ & Ref. \\
\hline $\begin{array}{l}\text { Dual-crosslinked network } \\
\text { from polydimethylsiloxane } \\
\text { (PDMS) }\end{array}$ & $\begin{array}{c}\text { Covalent } \\
\text { bond/ionic bond }\end{array}$ & N/A & 1.4 & 152 & $\mathrm{~S} 25$ \\
\hline $\begin{array}{l}\text { Dual-crosslinked network } \\
\text { from PDMS }\end{array}$ & $\begin{array}{c}\text { Boronic } \\
\text { ester/ionic bond }\end{array}$ & $\mathrm{N} / \mathrm{A}$ & 0.24 & 338 & S26 \\
\hline $\begin{array}{c}\text { Dual-crosslinked network } \\
\text { from epoxidized natural } \\
\text { rubber (ENR) }\end{array}$ & $\begin{array}{c}\text { Covalent } \\
\text { bond/ionic bond }\end{array}$ & N/A & 9.57 & 624 & S27 \\
\hline $\begin{array}{l}\text { Dual-crosslinked network } \\
\text { from poly(ethylene glycol) } \\
\text { (PEG) }\end{array}$ & $\begin{array}{c}\text { Covalent } \\
\text { bond/ionic bond }\end{array}$ & $\mathrm{N} / \mathrm{A}$ & 10 & 110 & S28 \\
\hline $\begin{array}{l}\text { Dual-crosslinked network } \\
\text { from polyacrylate }\end{array}$ & $\begin{array}{l}\text { DA bond/ionic } \\
\text { bond }\end{array}$ & N/A & 13 & 480 & S29 \\
\hline $\begin{array}{l}\text { Dual-crosslinked network } \\
\text { from ENR }\end{array}$ & $\begin{array}{c}\text { Covalent } \\
\text { bond/ionic bond }\end{array}$ & $\mathrm{N} / \mathrm{A}$ & 12 & 350 & $\mathrm{~S} 30$ \\
\hline $\begin{array}{l}\text { Dual-crosslinked network } \\
\text { from polybutadiene (PB) }\end{array}$ & $\begin{array}{c}\text { Imine } \\
\text { bond/ionic } \\
\text { hydrogen bond }\end{array}$ & N/A & 1.55 & 150 & S31 \\
\hline Double network of & Boron/oxygen & Miscible & 0.38 & 1171 & S32 \\
\hline
\end{tabular}




\begin{tabular}{|c|c|c|c|c|c|}
\hline $\begin{array}{l}\text { polyborosiloxane } \\
\text { (PBS)/PDMS }\end{array}$ & $\begin{array}{c}\text { dative } \\
\text { bond/hydrogen } \\
\text { bond }\end{array}$ & & & & \\
\hline $\begin{array}{l}\text { Double network of } \\
\text { PBS/PDMS }\end{array}$ & $\begin{array}{c}\text { Boron/oxygen } \\
\text { dative } \\
\text { bond/covalent } \\
\text { bond }\end{array}$ & Miscible & 0.47 & 1777 & S33 \\
\hline Polyacrylate based IPN & $\begin{array}{c}\text { DA } \\
\text { bond/hydrogen } \\
\text { bond }\end{array}$ & Miscible & 5.2 & 60 & S34 \\
\hline $\begin{array}{l}\text { Polyacrylate based double } \\
\text { network }\end{array}$ & Covalent bonds & Miscible & 13.2 & 145 & S35 \\
\hline $\begin{array}{c}\text { Polyacrylate based double } \\
\text { network }\end{array}$ & Covalent bonds & Miscible & 4.4 & 620 & S36 \\
\hline Polyacrylate based IPN & $\begin{array}{c}\text { DA } \\
\text { bond/hydrogen } \\
\text { bond }\end{array}$ & Miscible & 0.64 & 585 & S37 \\
\hline $\begin{array}{l}\text { IPN of SBR/polymethyl } \\
\text { methacrylate (PMMA) }\end{array}$ & Covalent bonds & $\begin{array}{c}\text { Immiscible, } \\
\text { phase-separated }\end{array}$ & 15.44 & 33.80 & S38 \\
\hline $\begin{array}{c}\text { IPN of silylated soybean } \\
\text { oil/PDMS }\end{array}$ & Covalent bonds & $\begin{array}{c}\text { Immiscible, } \\
\text { phase-separated }\end{array}$ & 0.45 & 19.95 & S39 \\
\hline $\begin{array}{c}\text { Double network of } \\
\text { cellulose/poly(ethyl } \\
\text { acrylate) }\end{array}$ & Covalent bonds & $\begin{array}{c}\text { Immiscible, } \\
\text { phase separated }\end{array}$ & 6.51 & 630 & S40 \\
\hline IPN of PDMS/PMMA & Covalent bonds & $\begin{array}{c}\text { Immiscible, } \\
\text { phase separated }\end{array}$ & 4.82 & 45 & S41 \\
\hline $\begin{array}{c}\text { IPN of PBS/poly(urea- } \\
\text { urethane) }\end{array}$ & $\begin{array}{l}\text { Disulfide } \\
\text { bond/borate } \\
\text { ester }\end{array}$ & $\begin{array}{l}\text { Immiscible, } \\
\text { phase separated }\end{array}$ & 1.90 & 1580 & S42 \\
\hline Blend of SBR/ENR & $\begin{array}{c}\text { Covalent } \\
\text { bond/coordinati } \\
\text { on bond }\end{array}$ & $\begin{array}{l}\text { Immiscible, } \\
\text { phase separated }\end{array}$ & 13.98 & 476 & S43 \\
\hline $\begin{array}{l}\text { IPN of polyurethane/(vinyl } \\
\text { or methacrylic polymer) }\end{array}$ & Covalent bonds & $\begin{array}{l}\text { Immiscible, } \\
\text { phase separated }\end{array}$ & 13 & 240 & S44 \\
\hline IPN of SBR/PMMA & Covalent bonds & $\begin{array}{l}\text { Immiscible, } \\
\text { phase separated }\end{array}$ & 13.31 & 73.21 & S45 \\
\hline ILN of SBR/PEI & $\begin{array}{l}\text { DA bond/imine } \\
\text { bond and ionic } \\
\text { interaction }\end{array}$ & $\begin{array}{l}\text { Immiscible, } \\
\text { homogeneous }\end{array}$ & 18.68 & 485.53 & $\begin{array}{l}\text { This } \\
\text { work }\end{array}$ \\
\hline
\end{tabular}


*The term 'dual-crosslinked network' represents the single-component polymer network, in which the macromolecular chains are crosslinked by two kinds of chemical bonds. One is covalent bond or dynamic covalent bond, and the other is noncovalent bond. Meantime, the term 'double network' represents the two-component polymer network, in which the two polymers are respectively crosslinked and the macromolecular chains from different networks interpenetrating with each other to give a co-network. As the definitions of 'double network' and 'IPN' are very close, the terminologies appearing in Table S5 are directly quoted from the corresponding references.

To evaluate the creep resistance, the commonly used four-parameter Burgers model, ${ }^{\mathrm{S} 46}$ which is a combination of Maxwell and Kelvin-Voigt element, is used to fit the creep curves.

$$
\varepsilon_{B}=\frac{\sigma_{0}}{E_{M}}+\frac{\sigma_{0}}{E_{K}}\left(1-e^{-t \frac{E_{K}}{\eta_{K}}}\right)+\frac{\sigma_{0}}{\eta_{M}} t
$$

where $\varepsilon_{B}$ is the sum creep strain, $\sigma_{0}$ is the applied stress, $t$ is the loading time, $E_{M}$ and $E_{K}$ are the moduli of Maxwell spring and Kelvin spring, $\eta_{M}$ and $\eta_{K}$ are the viscosities of Maxwell dashpot and Kelvin dashpot.

Table S6 Fitting parameters obtained from the Burgers model

\begin{tabular}{|c|c|c|c|c|}
\hline Sample & $E_{M}(\mathrm{MPa})$ & $\eta_{M}\left(\times 10^{3} \mathrm{MPa} \cdot \mathrm{s}\right)$ & $E_{K}(\mathrm{MPa})$ & $\eta_{K}\left(\times 10^{3} \mathrm{MPa} \cdot \mathrm{s}\right)$ \\
\hline
\end{tabular}




\begin{tabular}{|c|c|c|c|c|}
\hline SN-DA & 4.92 & 18.12 & 12.45 & 1216.92 \\
\hline ILN-201 & 11.77 & 18.98 & 13.24 & 913.26 \\
\hline ILN-202 & 12.35 & 29.30 & 15.13 & 981.81 \\
\hline ILN-203 & 10.85 & 22.78 & 11.03 & 784.15 \\
\hline ILN-204 & 11.22 & 18.464 & 11.00 & 1190.67 \\
& & & & 1157.22 \\
\hline Control-202 & 12.13 & 20.02 & 16.01 & 1349.12 \\
& & & & 11.61 \\
\hline Control-IPN & 11.43 & 14.92 & & \\
\hline
\end{tabular}

Generally, $E_{M}$ and $\eta_{M}$ reflect the recoverable instantaneous strain happened in the infancy of creep and the irrecoverable strain happened in the middle and later periods of creep, respectively. Both parameters increase when the ionic interactions are formed, which restrict the chains movement under long-period loading, so that ILN202 exhibits the most remarkable creep resistance. As for the two controls, whose creep resistance is lower than that of ILN-202, it can be explained by the fact that SNSchb is neither completely bonded nor interlocked. 
(a)

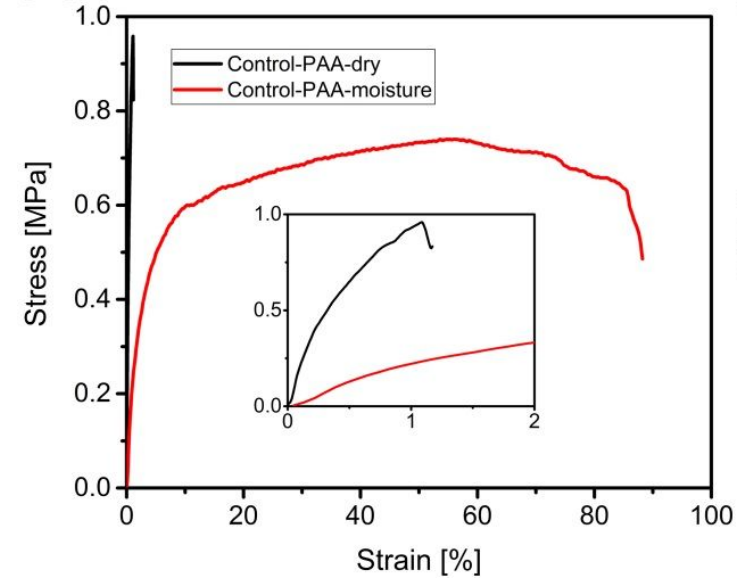

(b)

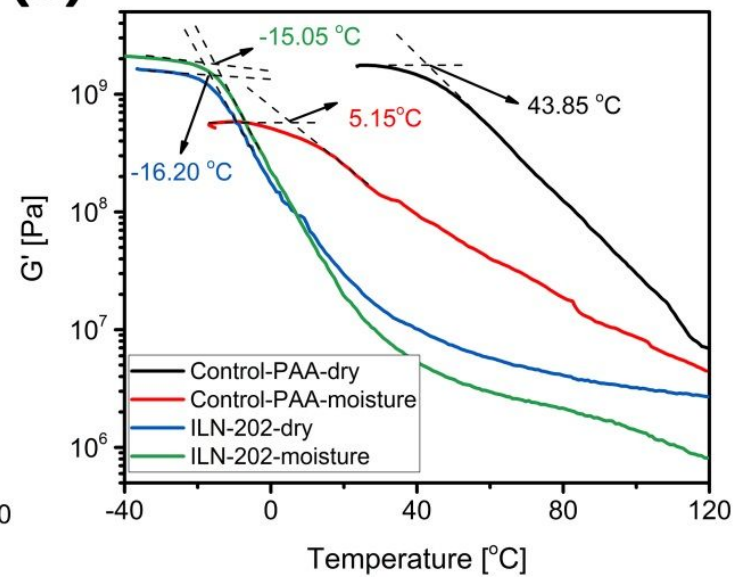

Figure S15 (a) Typical tensile curves of Control-PAA before and after exposure to moisture. (b) Comparison of temperature dependences of $G^{\prime}$ of ILN-202 and ControlPAA before and after exposure to moisture for $48 \mathrm{~h}$ at room temperature. 


\section{References}

S1. You, Y.; Peng, W. L.; Xie, P.; Rong, M. Z.; Zhang, M. Q.; Liu, D. Topological Rearrangement-Derived Homogeneous Polymer Networks Capable of Reversibly Interlocking: From Phantom to Reality and Beyond. Mater. Today 2020, 33, 45-55.

S2. Kuang, X.; Liu, G. M.; Dong, X.; Wang, D. J. Correlation Between Stress Relaxation Dynamics and Thermochemistry for Covalent Adaptive Networks Polymers. Mater. Chem. Front. 2017, 1, 111-118.

S3. Miwa, Y.; Taira, K.; Kurachi, J.; Udagawa, T.; Kutsumizu, S. A GasPlastic Elastomer That Quickly Self-Heals Damage with The Aid of $\mathrm{CO}_{2}$ Gas. Nat. Comm. 2019, 10, 1828.

S4. Enokida. J. S.; Hu, W.; Fang, H.; Morgan, B. F.; Beyer, F. L.; Winter, H. H.; Coughlin, E. B. Modifying the Structure and Dynamics of lonomers through Counterion Sterics. Macromolecules 2020, 53, 1767-1776.

S5. Yu, Z. X.; Wang, J.; Li, P. H.; Ding, D. C.; Zheng, X.; Hu, C. Q.; Gao, Z. N.; Hu, T.; Gong, X. H.; Wu, C. G. Melt Blending Modification of Commercial Polystyrene with Its Half Critical Molecular Weight, High Ion Content Ionomer, Poly(styrene-ran-cinnamic Acid) Zn Salt, toward Heat Resistance Improvement. Polymers 2020, 12, 584. 
S6. Rukmanikrishnan, B.; Kim, S. S.; Lee J. Flexible and compatible polymer composite blends based on polyurethane/sodium ionomer/lignin and their properties. J. Appl. Polym. Sci. 2020, 137, 48885.

S7. Manoj, N. R.; Ratna, D.; Dalvi, V.; Chandrasekhar, L.; Patri, M.; Chakraborty, B. C.; Deb, P. C. Interpenetrating Polymer Networks Based on Carboxylated Nitrile Rubber and Poly(Alkyl Methacrylate)s. Polym. Sci. Eng. 2002, 42, 1748-1755.

S8. Song, S. X.; Bi, X. J.; Jiang, S. K.; Lv, X.; Sun, S. L.; Li, Q. M. Enhanced Electroactive Phase, Toughness and Dielectric Properties of Poly(Vinylidene Fluoride) with Addition of MMA-BA-IL Copolymer. J. Polym. Res. 2018, 25, 157.

S9. Huang, D.; Ding, Y. L.; Jiang, H.; Sun, S. T.; Ma, Z.; Zhang, K. Y.; Pan, L.; Li, Y. S. Functionalized Elastomeric Ionomers Used as Effective Toughening Agents for Poly(lactic acid): Enhancement in Interfacial Adhesion and Mechanical Performance. ACS Sustainable Chem. Eng. 2020, 8, 573-585.

S10. Liu, H. Z.; Chen, F.; Liu, B.; Estep, G.; Zhang, J. W. Super Toughened Poly(lactic acid) Ternary Blends by Simultaneous Dynamic Vulcanization and Interfacial Compatibilization. Macromolecules 2010, 43, 6058-6066

S11. Dutta, S.; De, P. P.; De, S. K. Ionic Elastomer Blends of Zinc Salts of Maleated EPDM Rubber and Carboxylated Nitrile Rubber. J. Appl. Polym. Sci. 1998, 69, 153-160.

S12. Lopattananon, N.; Kraibut, A.; Sangjan, R.; Seadan, M. Ionic Elastomer 
Blends of Zinc Salts of Maleated Natural Rubber and Carboxylated Nitrile Rubber: Effect of Grafted Maleic Anhydride. J. Appl. Polym. Sci. 2007, 105, 1444-1455.

S13. Antony P.; De, S. K. Ionomeric Polyblends of Zinc Salts of Maleated EPDM Rubber and Poly(ethylene-co-acrylic acid). I. Effect of Blend Ratio. J. Appl. Polym. Sci. 1999, 71, 1247-1256.

S14. Su, Z. P.; Jiang, P. K.; Li, Q.; Wei, P.; Wang, G. L.; Zhang, Y. Mechanical Properties and Morphological Structures Relationship of Blends Based on Sulfated EPDM Ionomer and Polypropylene. J. Appl. Polym. Sci. 2004, 94, 15041510.

S15. Lee, J. W.; Kim, C. H.; Park, J. K.; Hwang, T. S. Study on the Microphase Structure and Mechanical Properties of the Blends of Acrylonitrile-ButadieneStyrene and Sodium Sulphonated Styrene-Acrylonitrile Ionomer. Polym. Int. 1998, 45, 47-54.

S16. Xie, H. Q.; Pan, Y. J.; Guo, J. S. Polymer Blends with Hydrogenated NitrileButadiene Rubber and with an Ionomer of Hydrogenated Carboxylic StyreneButadiene Rubber. J. Macromol. Sci. B 2003, 42, 257-268.

S17. Xie, H. Q.; Ao, Z. P.; Guo, J. S. Melt Flow and Mechanical Properties of Sulfonated SBR lonomers and Their Polymer Blends. J. Macromol. Sci. B 1995, 34, 249-262.

S18. Smith, M. J.; Verbeek, C. J. R. The Relationship Between Morphology 
Development and Mechanical Properties in Thermoplastic Protein Blends. $A d v$. Polym. Technol. 2018, 37, 1886-1896.

S19. Zhang, H. Q.; Li, X. F.; Zhao, C. J.; Fu, T. Z.; Shi, Y. H.; Na, H. Composite Membranes Based on Highly Sulfonated PEEK and PBI: Morphology Characteristics and Performance. J. Membrane Sci. 2008, 308, 66-74.

S20. Smitha, B.; Sridhar, S.; Khan, A. A. Polyelectrolyte Complexes of Chitosan and Poly(acrylic acid) As Proton Exchange Membranes for Fuel Cells. Macromolecules 2004, 37, 2233-2239.

S21. Guo, H. Y.; Fang, X.; Zhang, L.; Sun, J. Q. Facile Fabrication of RoomTemperature Self-Healing, Mechanically Robust, Highly Stretchable, and Tough Polymers Using Dual Dynamic Cross-Linked Polymer Complexes. ACS Appl. Mater. Interfaces 2019, 11, 33356-33363.

S22. Mohanty, S.; Vijavan, K.; Neelkantan, N. R.; Nando, G. B. Mechanical and Dynamic Mechanical Properties of Zinc Neutralized Salts of Poly(Ethylene coAcrylic Acid) and Its Blend With Epoxidized Natural Rubber. Polym. Sci. Eng. 1997, 37, 1395-1403.

S23. Seethamraju, S.; Ramamurthy, P. C.; Madras, G. Ionomer Based Blend as Water Vapor Barrier Material for Organic Device Encapsulation. ACS Appl. Mater. Interfaces 2013, 5, 4409-4416.

S24. Konovalova, A.; Kim, H.; Kim, S.; Lim, A.; Park, H. S.; Kraglund, M. R.; Aili, D.; Jang, J. H.; Kim. H.J.; Henkensmeier, D. Blend Membranes of 
Polybenzimidazole and An Anion Exchange Ionomer (FAA3) for Alkaline Water Electrolysis: Improved Alkaline Stability and Conductivity. J. Membrane Sci. 2018, 564, 653-662.

S25. Sun, H. B.; Liu, X. Y.; Yu, B.; Feng, Z. B.; Ning, N. Y.; Hu, G. H.; Tian, M.; Zhang, L. Q. Simultaneously Improved Dielectric and Mechanical Properties of Silicone Elastomer by Designing a Dual Crosslinking Network. Polym. Chem. 2019, 10, 633-645.

S26. Liu, Z.; Hong, P.; Xiang, H. P.; Huang, Z. Y.; Luo, Q. H.; Yang, X. J.; Liu, X. X. Preparation and Self-healability of Silicone Elastomer with Dualcrosslinked Network. Acta Polym. Sin. 2020, 51, 656-669.

S27. Liu, Y.; Li, Z. L.; Liu, R. J.; Liang, Z. P.; Yang, J.; Zhang R. L.; Zhou, Z. P.; Nie, Y. J. Design of Self-Healing Rubber by Introducing Ionic Interaction to Construct a Network Composed of Ionic and Covalent Cross-Linking. Ind. Eng. Chem. Res. 2019, 58, 14848-14858.

S28. Cristiani, T. R.; Filippidi, E.; Behrens, R. L.; Valentine, M. T.; Eisenbach, C. D. Tailoring the Toughness of Elastomers by Incorporating lonic CrossLinking. Macromolecules 2020, 53, 10, 4099-4109.

S29. Peng, Y.; Yang, Y.; Wu, Q.; Wang, S. X.; Huang, G. S.; Wu, J. R. Strong and Tough Self-Healing Elastomers Enabled by Dual Reversible 
Networks Formed by lonic Interactions and Dynamic Covalent Bonds. Polymer 2018, 157, 173-179.

S30. Zhang, Y. K.; Li, H.; Li, C. L.; Chen, X.; Lesser, A. Investigation of "Zn2+ Salt-Bondings" Cross Linked ENR with Shape Memory Effect via Ionic Interactions. Polym. Eng. Sci. 2018, 59, E367-E374.

S31. Zhang, H.; Wang, D.; Wu, N. N.; Li, C. H.; Zhu, C. Z.; Zhao, N.; Xu, J. Recyclable, Self-Healing, Thermadapt Triple-Shape Memory Polymers Based on Dual Dynamic Bonds. ACS Appl. Mater. Interfaces 2020, 12, 9833-9841.

S32. Qu, P. Y.; Lv, C.; Qi, Y. H.; Bai, L.; Zheng, J. P. A Highly Stretchable, SelfHealing Elastomer with Rate Sensing Capability Based on a Dynamic Dual Network. ACS Appl. Mater. Interfaces 2021, 13, 9043-9052.

S33. Wu, Q.; Xiong, H.; Peng, Y.; Yang, Y.; Kang, J.; Huang, G. S.; Ren, X. C.; Wu, J. R. Highly Stretchable and Self-Healing "Solid-Liquid" Elastomer with Strain-Rate Sensing Capability. ACS Appl. Mater. Interfaces 2019, 11, 19534-19540.

S34. Zhang, B. R.; Ke, J.; Vakil, J. R.; Cummings, S. C.; Digby, Z. A.; Sparks, J. L.; Ye, Z. J.; Zanjani, M. B.; Konkolewicz, D. Dual-Dynamic 
Interpenetrated Networks Tuned Through Macromolecular Architecture. Polym. Chem. 2019, 10, 6290-6304.

S35. Ducrot, E.; Chen, Y.; Bulters, M.; Sijbesma, R. P.; Creton, C. Toughening Elastomers with Sacrificial Bonds and Watching Them Break. Science 2014, 344, 186-189.

S36. Zhang, H.; Zeng, D. Z.; Pan, Y. F.; Chen Y. J.; Ruan Y. H.; Xu, Y. Z.; Boulatov, R.; Creton, C.; Weng, W. G. Mechanochromism and Optical Remodeling of Multi-Network Elastomers Containing Anthracene Dimers. Chem. Sci. 2019, 10, 8367-8373.

S37. Foster, E. M.; Lensmeyer, E. E.; Zhang, B. R.; Chakma, P.; Flum, J. A.; Via J. J.; Sparks, J. L.; Konkolewicz, D. Effect of Polymer Network Architecture, Enhancing Soft Materials Using Orthogonal Dynamic Bonds in an Interpenetrating Network. ACS Macro Lett. 2017, 6, 495-499.

S38. James, J.; Thomas, G. V.; Madathil, A. P.; Nambissan, P. M. G.; Kalarikkal, N.; Thomas, S. Positron Annihilation Spectroscopic Characterization of Free-Volume Defects and Their Correlations with The Mechanical and Transport Properties of SBR-PMMA Interpenetrating Polymer Networks. Phys. Chem.Chem.Phys. 2020. 22, 18169-18182. 
S39. Dewasthale, S.; Andrews, C.; Narayan, R.; Graiver, D. Interpenetrating Polymers Networks Derived from Silylated Soybean Oil and Water Soluble Polysiloxanes. J. Appl. Polym. Sci. 2019, 136, 47182.

S40. Murai, J.; Nakajima, T.; Matsuda, T.; Tsunoda, K.; Nonoyama, T.; Kurokawa, T.; Gong, J. P. Tough Double Network Elastomers Reinforced by The Amorphous Cellulose Network. Polymer 2019, 179, 121686.

S41. Silvaroli, A. J.; Heyl, T. R.; Qiang, Z.; Beebe, J. M.; Ahn, D.; Mangold, S.; Shull, K. R.; Wang, M. Z. Tough, Transparent, Photocurable Hybrid Elastomers. ACS Appl. Mater. Interfaces 2020, 12, 44125-44136.

S42. Martin, R.; Rekondo, A.; de Luzuriaga, A. R.; Santamaria, A.; Odriozola, I. Mixing The Immiscible: Blends of Dynamic Polymer Networks. RSC Adv. 2015, 5, 17514-17518.

S43. Zhang, X. H.; Liu, J.; Zhang, Z. Y.; Wu, S. W.; Tang, Z. H.; Guo, B. C.; Zhang, L. Q. Toughening Elastomers Using a Mussel-Inspired Multiphase Design. ACS Appl. Mater. Interfaces 2018, 10, 23485-23489.

S44. Xie, H. Q.; Guo, J. S. Room Temperature Synthesis and Mechanical Properties of Two Kinds of Elastomeric Interpenetrating Polymer Networks Based on Castor Oil. European Polymer Journa/2002, 38, 2271-2277. 
S45. James, J.; Thomas, G. V.; Thomas, S. Fabrication of Interpenetrating Polymer Networks of SBR and PMMA with Nano Domains. Materials Today: Proceedings 2019, 9, 77-84.

S46. Yao, Z, Wu, D. F.; Chen, C.; Zhang, M. Creep Behavior of Polyurethane Nanocomposites with Carbon Nanotubes. Compos. Part AAppl. S. 2013, 50, 65-72. 